\title{
Neighborhood Resources for Physical Activity and Healthy Foods and Their Association With Insulin Resistance
}

\author{
Amy H. Auchincloss, * Ana V. Diez Roux, * Daniel G. Brown, $\dagger$ Christine A. Erdmann,* \\ and Alain G. Bertoni
}

\begin{abstract}
Objective: Little is known about the influence of the built environment, and in particular neighborhood resources, on health. We hypothesized that neighborhood resources for physical activity and healthy foods are associated with insulin resistance.

Methods: Person-level data $(n=2026)$ came from 3 sites of The Multi-Ethnic Study of Atherosclerosis, a study of adults aged 45-84 years. Area-level data were derived from a population-based residential survey. The homeostasis model assessment index was used as an insulin resistance measure among persons not treated for diabetes. We used linear regression to estimate associations between area features and insulin resistance.

Results: Greater neighborhood physical activity resources consistently were associated with lower insulin resistance. Adjusted for age, sex, family history of diabetes, race/ethnicity, income and education, insulin resistance was reduced by $17 \%(95 \%$ confidence interval $=-31 \%$ to $-1 \%$ ) for an increase from the 10 th to 90 th percentiles of resources. Greater healthy food resources were also inversely related to insulin resistance, although the association was not robust to adjustment for race/ethnicity. Analyses including diet, physical activity, and body mass index suggested that these variables partly mediated observed associations. Results were similar when impaired fasting glucose/diabetes was considered as the outcome variable.
\end{abstract}

Conclusion: Diabetes prevention efforts may need to consider features of residential environment.

(Epidemiology 2008;19: 146-157)

P revalence of type 2 diabetes and metabolic abnormalities is rising. Little area-level research has been devoted to understanding environmental determinants of this epidemic.

Submitted 17 February 2007; accepted 14 August 2007.

From the *Department of Epidemiology, School of Public Health and $\dagger$ School of Natural Resources and Environment, University of Michigan, Ann Arbor, Michigan; and †Department of Public Health Sciences, Wake Forest University School of Medicine, Winston-Salem, North Carolina.

Supported by contracts N01-HC-95159 through N01-HC-95166 from the National Heart, Lung, and Blood Institute. Also supported in part by R01 HL071759 (to A.V.D.R.).

Correspondence: Amy H. Auchincloss, Department of Epidemiology, School of Public Health, University of Michigan, 109 Observatory Street, Room 3667 SPH I, Ann Arbor, MI 48109-2029. E-mail: aauchinc@umich.edu. Copyright (C) 2008 by Lippincott Williams \& Wilkins

ISSN: $1044-3983 / 08 / 1901-0146$

DOI: $10.1097 /$ EDE.0b013e31815c480
Residential environments may affect both diet and physical activity, 2 important risk factors for metabolic abnormalities. Two studies ${ }^{1,2}$ have provided empirical evidence of an association between area socioeconomic disadvantage and a measure of metabolic abnormalities - insulin resistance- but no study has examined specific features of residential environments that may contribute to insulin resistance.

Resources for physical activity and availability of healthy foods are specific features of residential environments that may be related to the prevalence of diabetes and metabolic abnormalities among residents. The availability of high-quality fruits and vegetables and of low-fat foods may be an important determinant of a healthy diet. For example, supermarket prevalence has been positively associated with a healthy diet ${ }^{3,4}$ and negatively associated with obesity. ${ }^{5}$ Walking destinations and opportunities for physical activity, such as parks and recreational facilities, may increase the likelihood that residents will be physically active. ${ }^{6}$ Density of facilities for physical activity in a neighborhood has been positively associated with physical activity ${ }^{7,8}$ and negatively associated with obesity. ${ }^{9}$ These environmental features have not been considered in relation to insulin resistance.

\section{Hypotheses}

We examined the cross-sectional association of availability of healthy foods and suitability of the residential environment for physical activity with insulin resistance in a population-based sample in 3 areas in the Eastern United States. We hypothesized that insulin resistance is inversely associated with these 2 area features. We also hypothesized that diet and physical activity mediate these associations, both directly and via obesity. Because residents are not restricted to their immediate residential neighborhoods, we also hypothesized that distance to areas with good availability of healthy foods and good resources for physical activity are positively associated with insulin resistance.

\section{METHODS}

\section{Person-Level Data}

Person-level data used in these analyses came from a cohort study of atherosclerosis, the Multi-Ethnic Study of Atherosclerosis. This study recruited persons age $45-84$ years from 6 sites using a variety of population-based approaches, including 
commercial lists of area residents and random digit dialing, as previously reported. ${ }^{10}$ Only persons free of clinical cardiovascular disease were eligible. For this analysis we used baseline data (collected 2000-2002) from the 3 sites for which neighborhood-level data were obtained: Baltimore City and County, Maryland; Forsyth County, North Carolina; and New York and Bronx counties, New York.

Our primary interest was to examine how environmental conditions may contribute to early metabolic abnormalities. We measured insulin resistance using a continuous index (the homeostasis model assessment index) among persons not treated for diabetes. This index is calculated as [fasting insulin $(\mu \mathrm{U} / \mathrm{mL}) \times$ fasting glucose $(\mathrm{mmol} / \mathrm{L})] / 22.5$, and is well correlated with measures from the gold-standard hyperinsulinemic clamp $\left(r=0.88^{11}\right)$ - the most widely used surrogate measure of insulin resistance in epidemiologic studies. ${ }^{12}$ Values of this index were highly skewed and were therefore $\log$ transformed for multivariable analyses. Because persons treated for diabetes were excluded from these analyses, supplementary analyses used a binary variable that combined impaired fasting glucose and diabetes (as defined by the American Diabetes Association 2003 criteria $^{13}$ ).

Information on person-level covariates [age, sex, race/ ethnicity, family history of diabetes, income, education, physical activity, dietary intake, and body mass index (BMI)] was obtained during the clinic examination. Family history of diabetes was positive if at least 1 blood-relative parent and at least 1 blood-relative sibling had diabetes. ${ }^{14}$ Participants selected their total combined family income for the past 12 months from 13 income categories. Per capita income was calculated by dividing the interval midpoint of the selected family income category by the number of persons supported. Participants selected their education from 8 categories, and continuous years of education was assigned as the interval midpoint of the selected education category.

Because moderate and vigorous physical activity are known to be inversely associated with insulin resistance, ${ }^{15,16}$ we estimated metabolic equivalent task-minutes for walking and moderate and vigorous intensity sports and conditioning activities from a physical activity questionnaire. ${ }^{10,17}$ Physical activity measures were skewed and so were log transformed for multivariable analyses. We selected dietary measurements (compiled from a food frequency questionnaire ${ }^{10}$ ) that may protect against insulin resistance: daily total dietary fiber and servings per day of low-fat dairy. Diets higher in fiber ${ }^{18-20}$ and dairy ${ }^{18,21}$ have been associated with less insulin resistance for their intrinsic properties or because they are proxies for a "healthy" diet. ${ }^{18,22}$

\section{Area-Level Data}

Measures of area resources were obtained from an independent sample: the Community Survey ${ }^{23}$ a population-based random-digit-dialing telephone survey conducted as part of an ancillary study, the Multi-Ethnic Study of Atherosclerosis
Neighborhood Study. ${ }^{10}$ (We used a sample that was independent but colocated with the original study's sites/participants to avoid spurious associations that can result when neighborhood information and behaviors are self-reported. ${ }^{24,25}$ ) Community Survey data were collected in 2004 from 5988 persons residing in Baltimore, Forsyth, and New York. The survey collected information on a number of neighborhood-level domains potentially related to cardiovascular disease. Two scales were used in this analysis: suitability of the environment for physical activity and availability of healthy foods. (See Table 1 footnote for list of scale items.) Both scale internal consistency and test-retest reliability were acceptably high (Cronbach $\alpha \geq 0.73$, test-retest 2 weeks postsurvey $\geq 0.60$ ), as previously reported. ${ }^{23}$ To derive area characteristics (latitude/longitude) for each residence of participants in The Multi-Ethnic Study of Atherosclerosis, scales were modeled spatially across each study site using spatial error regression. These regression models used supplementary data (2000 US census block group socio-demographic data, InfoUSA Inc. food retailer data, ${ }^{26,27}$ and recreational facility data ${ }^{8}$ ) to improve prediction. Methodologic details of this method are provided elsewhere. ${ }^{2}$ The modeled data characterize a 1-mile area around the residence.

Because participants in The Multi-Ethnic Study of Atherosclerosis are not restricted to the 1-mile around their residence, Euclidean distances were computed between their residences and the closest neighborhood with above-median ("good") suitability for physical activity and above-median ("good") availability of healthy foods. Neighborhood resources for the distance measures were derived by applying the spatial error regression model (described above) to a grid of $300 \mathrm{~m}^{2}$

\section{Participants Included in Study}

Of the 3265 participants at baseline residing in the 3 study sites, 2963 agreed to participate in the ancillary neighborhood study. ${ }^{10}$ Of these persons, 92 were excluded because of address errors and 645 because of missing information on outcome, exposure, or key covariates. Data on the remaining 2226 participants were available for secondary analyses that examined the binary impaired fasting glucose/diabetes variable. In primary analyses that used the continuous homeostasis model assessment index as the outcome, an additional 200 individuals were excluded because they used oral hypoglycemic agents or insulin that would medically alter glucose or insulin levels. This left 2026 participants for analyses. Demographic characteristics of persons included in primary analyses $(\mathrm{n}=2026)$ were similar to excluded persons $(n=1239)$ except that excluded participants were less likely to be white ( $32 \%$ vs. $45 \%$ ) and more likely to be African-American (54\% vs. $40 \%)$; had lower income $(\$ 24,000$ vs. $\$ 28,000$ per capita family income) and lower education (12.8 vs. 13.6 years education); and had somewhat higher BMI (29.5 vs. $\left.28.9 \mathrm{~kg} / \mathrm{m}^{2}\right)$. All participants provided written informed consent. 


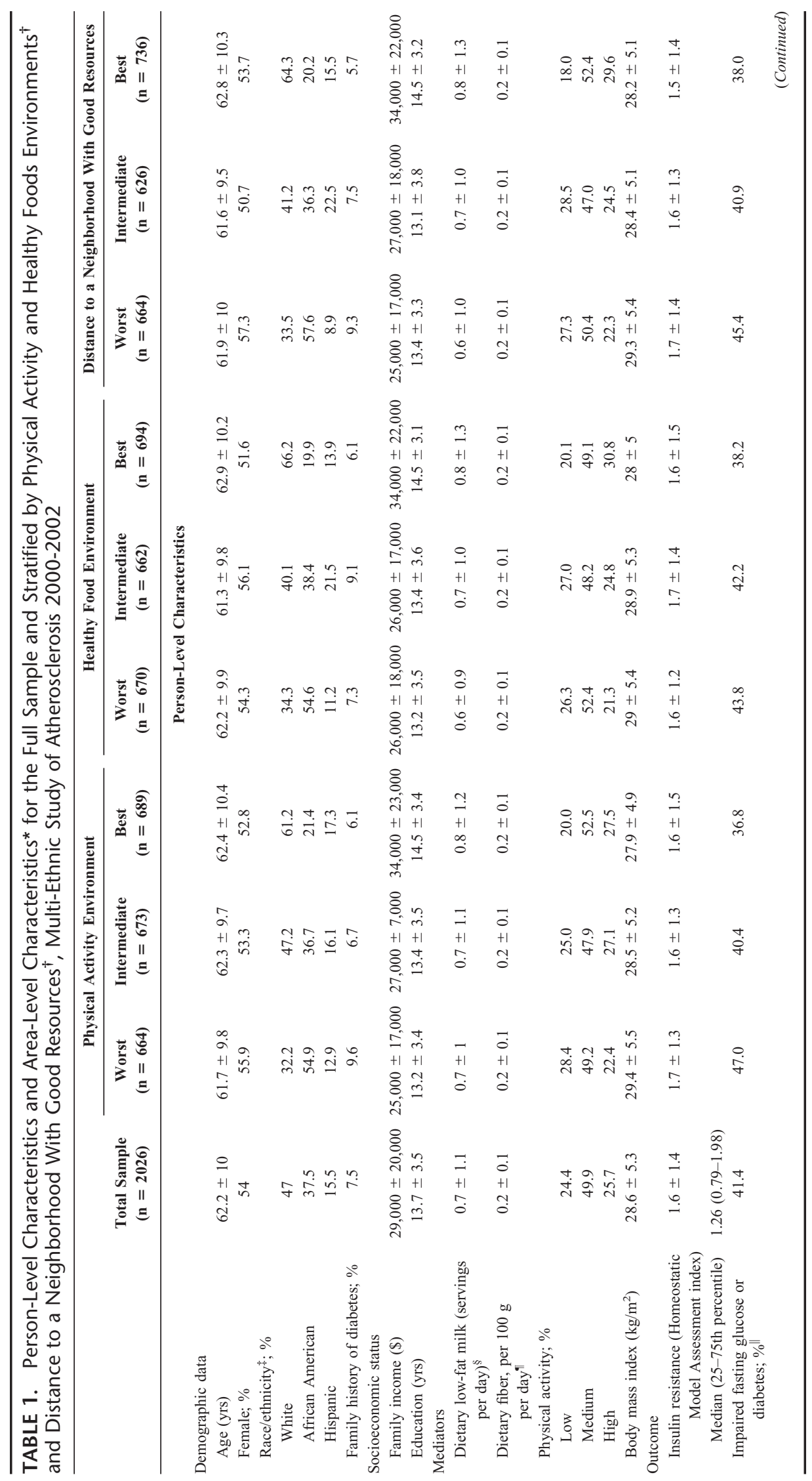




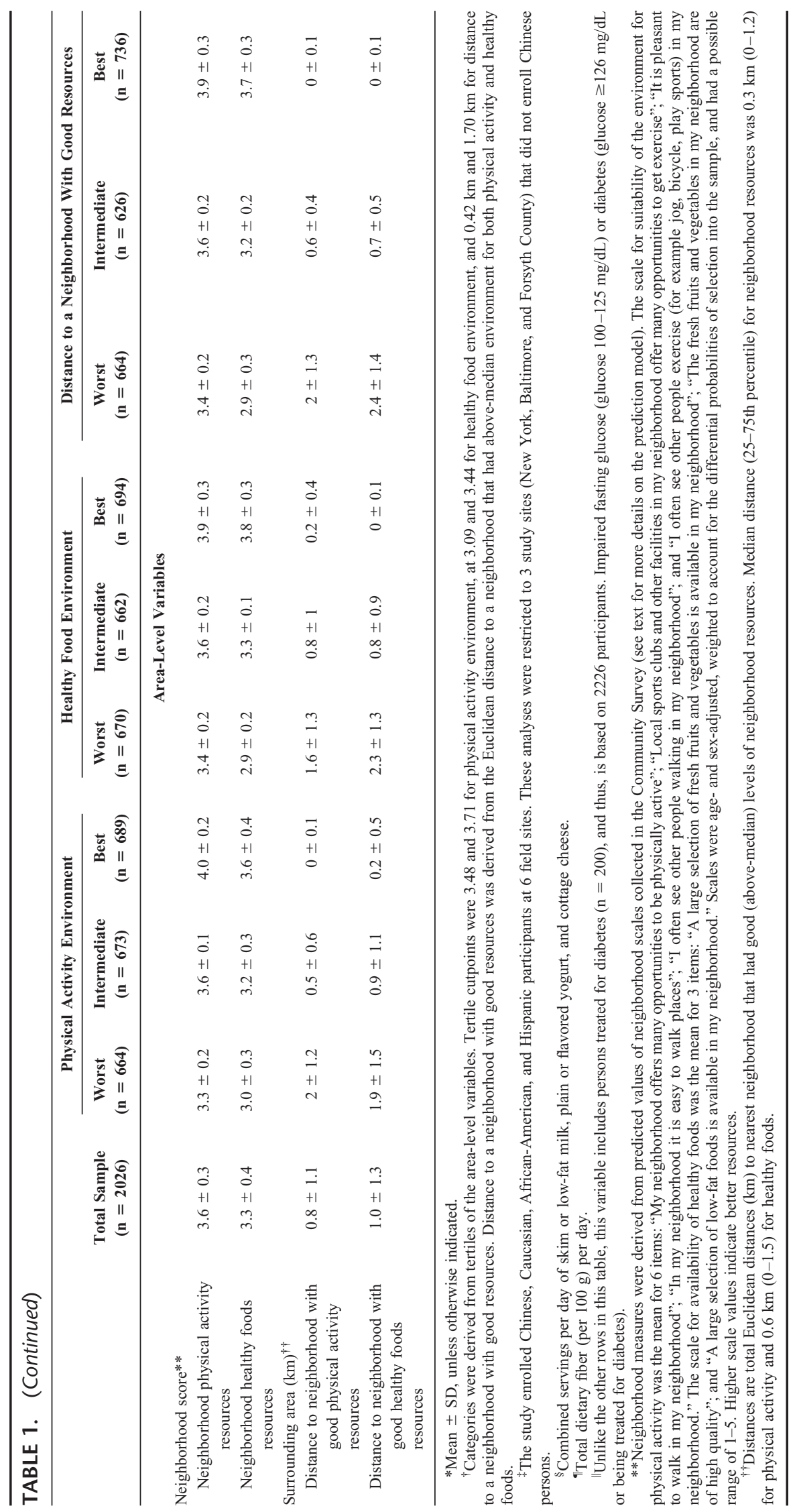




\section{Statistical Analyses}

We first examined unadjusted correlations between variables as well as the distribution of individual-level variables by tertiles of neighborhood resources for ${ }^{1}$ physical activity, ${ }^{2}$ healthy foods, and ${ }^{3}$ distance to a neighborhood with both above-median physical activity and healthy foods. Ordinary least squares regression was used to separately estimate adjusted associations of the following variables with insulin resistance: neighborhood resources for physical activity; neighborhood resources for healthy foods; distance to a neighborhood with good resources for physical activity; and distance to a neighborhood with good resources for healthy foods. Analyses controlled for age, sex, family history of diabetes, income, and education. Because it has often been difficult to separate area effects from race/ethnicity effects due to strong spatial patterning by race/ethnic composition, ${ }^{28}$ models were examined before and after adjustment for race/ ethnicity.

We investigated whether associations differed by household automobile ownership, study site, years of residence in the neighborhood, and shopping for food and exercising within 1 mile of the participant's residence. These variables were thought to potentially modify associations between area features and insulin resistance for the following reasons: persons who have access to transportation (via automobile) may be less confined to their neighborhoods and thus their area effects may be attenuated $^{29-31}$; characteristics of prior neighborhoods may differ from the current neighborhood, which may lead to weaker crosssectional relationships for residents who had moved into the neighborhood; associations may be weaker for persons who routinely access resources outside the neighborhood reported on by Community Survey participants; study site may signify differences in transportation infrastructure, public investment and commerce, all of which may modify area effects. Heterogeneity of effects were examined using stratified analyses and by including appropriate interaction terms in regression models.

Two approaches were used to examine our secondary hypothesis that individual-level diet, physical activity, and BMI are intermediaries in the pathway between area characteristics and insulin resistance. First, results from the primary analyses were examined before and after adjustment for physical activity, diet, and BMI. We expected that the magnitude of associations between insulin resistance and area features would be attenuated after including these variables. Second, because of the difficulty in estimating direct and indirect effects by controlling for potential mediators, ${ }^{32}$ the suspected mediating variables (physical activity, diet, and BMI) also were examined as outcome variables regressed onto area features. When used as outcome variables, physical activity (total hours per day) and diet (mean of servings per day of whole grain/cereal fiber and low-fat diary) were log transformed.
For ease of interpretation, regression results are reported as percent differences for outcomes that were logtransformed $[100 \times($ exponentiated mean difference -1$)]$ or binary $[100 \times($ exponentiated prevalence difference -1$)]$. To compare associations for area level variables that have different units, estimates shown correspond to differences between the 90th and 10th percentiles of the area-level variable [translating to a difference of 1.92 in the physical activity scale, 2.62 in the healthy foods scale, $2.70 \mathrm{~km}$ (1.68 miles) in the distance to good physical activity resources, and $2.97 \mathrm{~km}$ (1.85 miles) in the distance to good healthy foods resources]. We also computed $95 \%$ confidence intervals (CIs) for all multivariable analyses.

Generalized additive models ${ }^{33}$ were used to explore nonlinear relations between the independent variables and the outcome variable while adjusting for covariates. There was no evidence of strong threshold effects among the area-level variables and therefore these were fit as continuous variables. Distance measures were square-root-transformed to better model the functional form of their adjusted relation with insulin resistance.

We examined the sensitivity of results to excluding persons treated for diabetes by conducting separate analyses using $\log$ binomial regression ${ }^{34}$ with the presence of impaired fasting glucose/diabetes as the outcome. We also examined the sensitivity of results to alternate neighborhood measures by aggregating survey responses to census tracts using empirical Bayes estimation $^{35}$ and the crude mean. Additional sensitivity analyses used spatial error regression to model residual spatial dependence in models where the homeostasis model assessment index was the outcome. ${ }^{36}$

\section{RESULTS}

\section{Descriptive Results}

Table 1 shows characteristics of the study sample. Mean neighborhood score was higher for physical activity than for healthy foods (3.6 and 3.3, respectively). Only $22 \%$ of study participants resided in a neighborhood that was an above-median environment for physical activity and healthy foods. Participants were relatively close to environments with above-median resources [median distance $0.3 \mathrm{~km}$ ( 0.2 miles) for physical activity and $0.6 \mathrm{~km}$ ( 0.4 miles) for healthy foods] although median distance between residences and neighborhoods that had abovemedian resources for both characteristics was substantially greater [1.5 km (1.9 miles)]. Living in neighborhoods with better physical activity and healthy food environments or living closer to neighborhoods with favorable environments was associated with white race, lower family history of diabetes, higher income, higher education, lower BMI, generally better physical activity and dietary profiles (except for dietary fiber intake), and lower insulin resistance (Table 1). Study participants traveled a median of 3.5 miles to shop for food and 0.5 miles to exercise (among persons who engaged in physical activity). Participants resided 
in their neighborhood for a median of 17 years (interquartile range 8-30 years, not shown in tables).

There was only low/moderate correlation between family income and the area-level variables (Pearson $r<0.25$, bivariate correlations not shown in tables). However, correlations were high (Pearson $r>0.65$, not shown) between variables for physical activity and healthy food resources, thus prohibiting examination of their independent effects.

\section{Main Associations}

Adjusted for age, sex, family history of diabetes, income, and education (column B), insulin resistance was negatively associated with neighborhood resources for physical activity and for healthy foods (Table 2). Improvements in neighborhood resources (corresponding to the difference between 90th and 10th percentiles) were associated with $23 \%$ lower insulin resistance for physical activity resources $(95 \%$ $\mathrm{CI}=-35 \%$ to $-8 \%)$ and $15 \%$ lower for healthy foods resources $(\mathrm{CI}=-30 \%$ to $2 \%)$. After adjustment for race/ ethnicity (column C), physical activity resources remained robust $(-17 \%$; CI $=-31 \%$ to $-1 \%)$, however, associations were markedly attenuated for healthy food resources $(-6 \%-22 \%$ to $14 \%)$.

Insulin resistance also was positively associated with distance to an area with good resources. Distance to resources (corresponding to the difference between the 90th and 10 percentiles) was associated with $10 \%$ higher insulin resistance for physical activity resources $(1 \%-18 \%)$ and $8 \%$ for healthy foods resources $(0 \%-15 \%)$, adjusted for age, sex, family history of diabetes, income, and education. Once again, associations were attenuated after adjustment for race/ ethnicity.

\section{Potential Mediators}

As expected, additional adjustment for person-level physical activity, diet, and BMI reduced associations between insulin resistance and area-level resources (Table 2, column D and E). For example, improvements in neighborhood physical activity environments were associated with $17 \%$ lower insulin resistance before adjustment for potential mediators; $11 \%$ lower insulin resistance after adding person-level diet and physical activity $(\mathrm{CI}=-26 \%$ to $6 \%$; model $1 \mathrm{D})$, and $1 \%$ lower insulin resistance after adding BMI ( $-15 \%$ to $16 \%$; model $1 \mathrm{E})$.

When we examined BMI, physical activity, and diet as outcome variables, we found these outcomes generally were associated with area-level characteristics in the expected directions (Table 3). For example, after adjustment for age, sex, family history of diabetes, income, education, and race/ ethnicity (model C), improvements in neighborhood physical activity environments were associated with 2.03 lower BMI $(-3.41$ to -0.66$)$ and $73 \%$ more exercise hours $(37 \%-$ $118 \%$ ). As expected, associations between area-level variables and BMI were reduced after individual-level physical activity and diet were added to the model (model D). Area- level healthy foods resources were related to better diet, but associations were reduced to null after race/ethnicity was added to the model.

\section{Interactions}

Table 4 shows variables for which tests for interactions were $P \leq 0.06$ with either neighborhood or distance to healthy foods. In general, the association between insulin resistance and healthy foods resources was stronger for persons who did not own an automobile, shopped for food within 1 mile of their home, and lived at the New York site. The association between neighborhood physical activity resources and insulin resistance was stronger for persons who exercised within 1 mile of their home [among those who exercised at all, for a change from the 10th to 90th percentiles in neighborhood physical activity resources, insulin resistance decreased $27 \%$ (CI $=-46 \%$ to 0$)$ vs. $39 \%$ ( -14 to 124$)$ for exercising $>1$ mile; $P$ for interaction $=0.02]$. Associations between physical activity resources and insulin resistance were not modified by automobile ownership or study site (all tests for interaction $P \geq 0.2$ ). Years in the neighborhood did not modify associations between insulin resistance and healthy food nor physical activity resources (all tests for interaction $P \geq 0.1$ ).

\section{Sensitivity Analyses}

Results were similar when participants treated for diabetes were included in analyses-using impaired fasting glucose/diabetes in place of the homeostasis model as a measure of insulin resistance (Table 5; $\mathrm{n}=2226$ ). For example, adjusted for age, sex, family history of diabetes, race/ethnicity, income and education (column B), the prevalence was $21 \%$ lower ( $-41 \%$ to $6 \%$ ) with improvements in physical activity resources and $17 \%$ higher $(4 \%-31 \%)$ with farther distances to a neighborhood with good physical activity resources.

Spatial dependence statistics indicated no statistically significant dependence among model residuals ${ }^{37}$ and spatial autocorrelation models yielded similar results, although CIs were wider. The direction of associations between insulin resistance and neighborhood resources remained the same when two-mile averages and tract-level aggregations were used in place of spatial interpolation estimates, even though CI widths changed (wider for physical activity resources and narrower for healthy foods, not shown).

\section{DISCUSSION}

In this cross-sectional study, insulin resistance was negatively associated with suitable residential environments for physical activity and for purchasing healthy foods. Associations between insulin resistance and physical activity environments persisted after adjustment for individual levelvariables. For example, adjusted for age, sex, family history of diabetes, race/ethnicity, income and education, insulin 


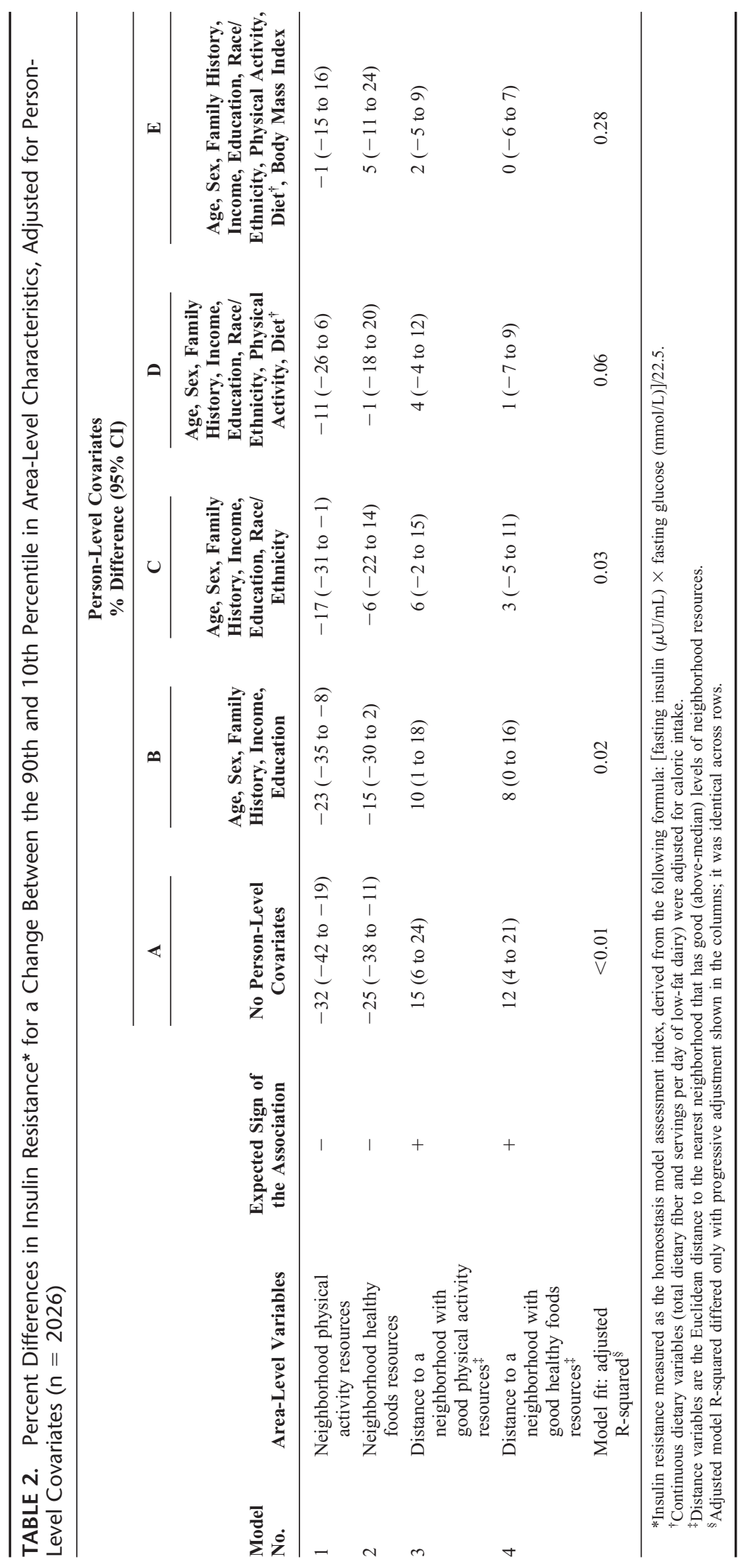




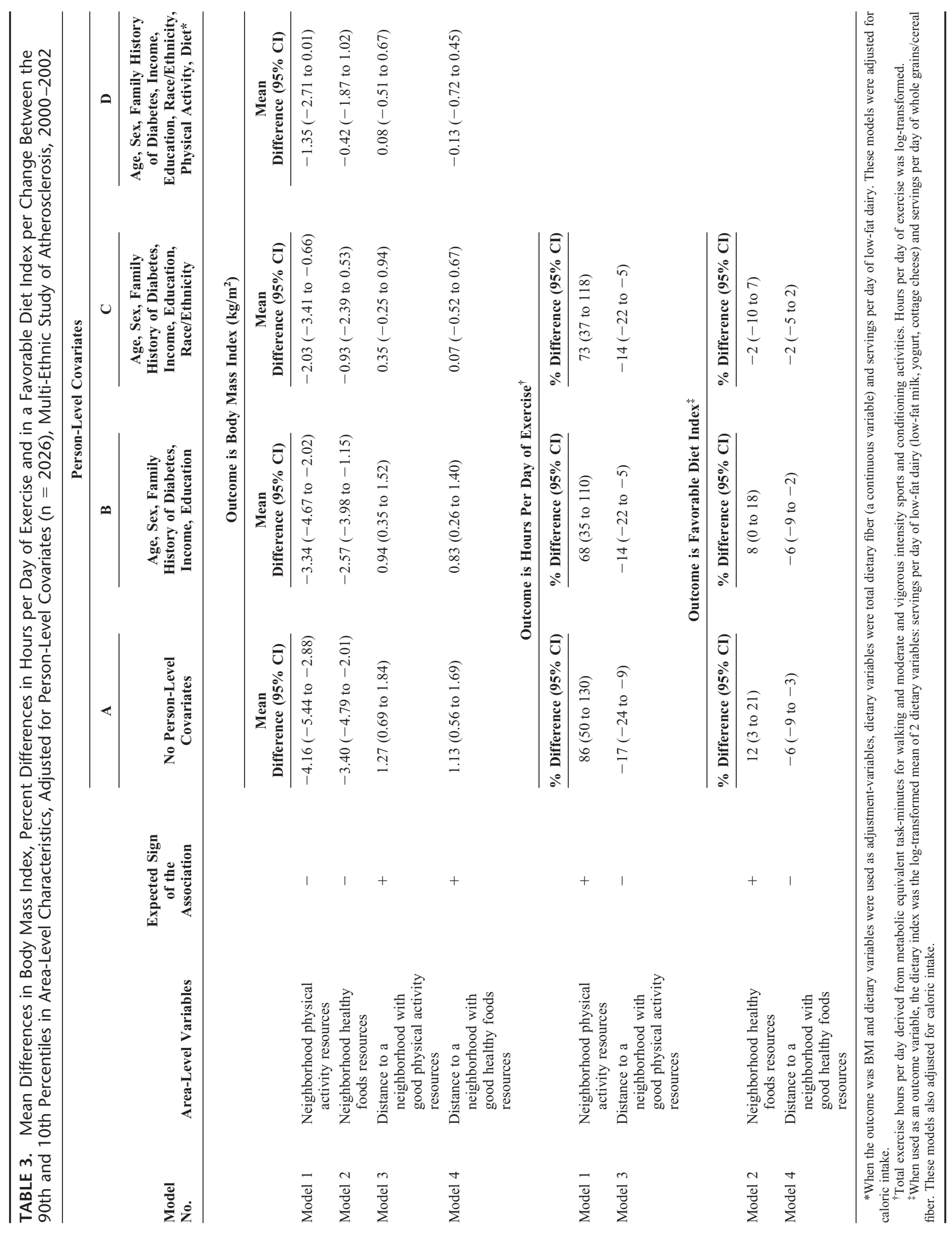


TABLE 4. Stratified Percent Differences in Insulin Resistance* for a Difference Between the 90th and 10th Percentile in Neighborhood Resources for Healthy Foods and for Distance to a Neighborhood With Good Resources for Healthy Foods

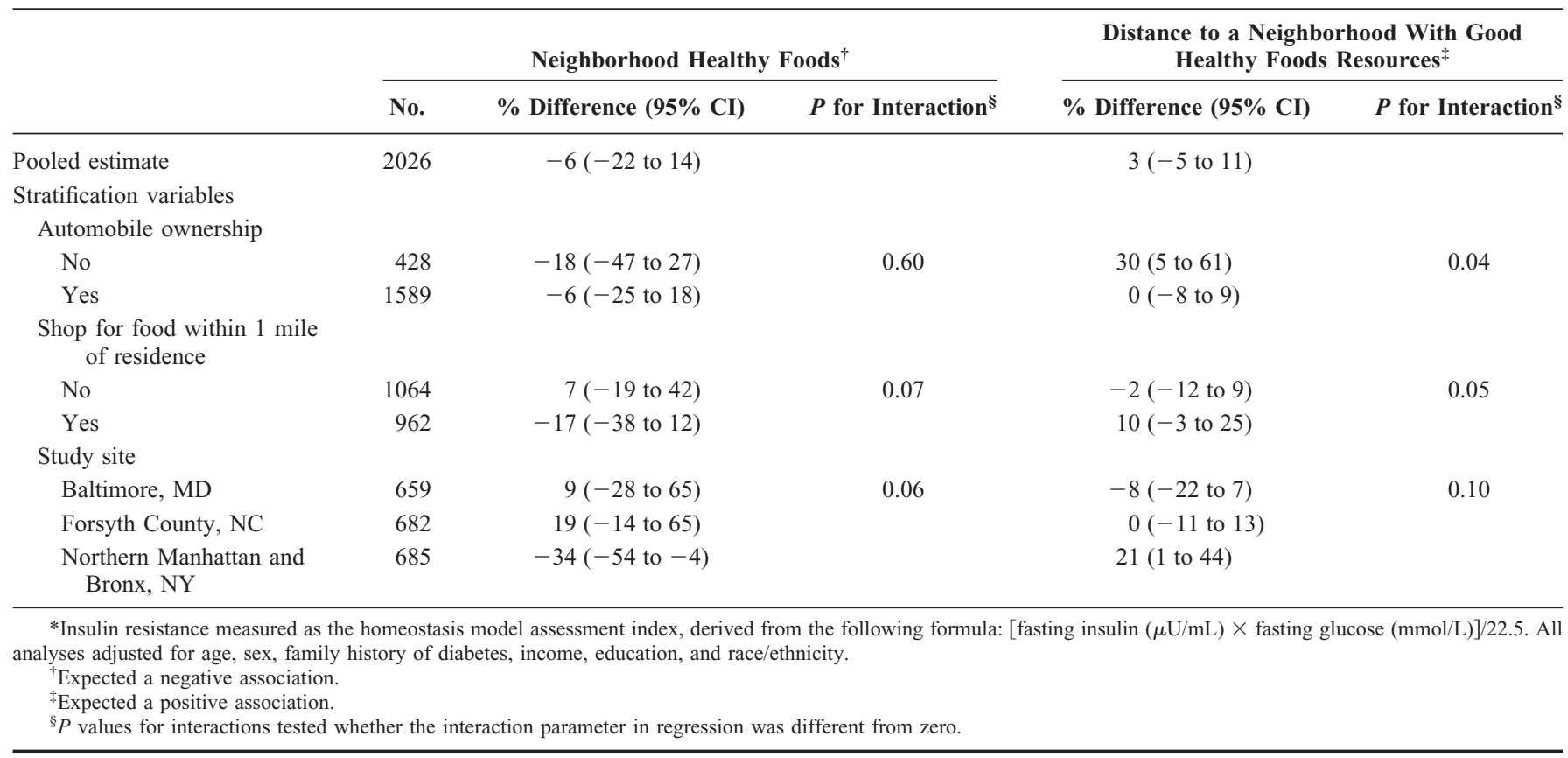

TABLE 5. Percent Differences in Prevalence of Impaired Fasting Glucose/Diabetes* for a Change Between the 90th and 10th Percentile in Area-Level Characteristics, Adjusted for Person-Level Covariates $(n=2226)$

\begin{tabular}{|c|c|c|c|c|c|c|}
\hline \multirow[b]{3}{*}{ Model No. } & \multirow[b]{3}{*}{ Area-Level Variables } & \multicolumn{5}{|c|}{$\begin{array}{l}\text { Person-Level Covariates } \\
\% \text { Difference }(95 \% \text { CI) }\end{array}$} \\
\hline & & $\mathbf{A}$ & B & $\mathbf{C}$ & D & $\mathbf{E}$ \\
\hline & & $\begin{array}{c}\text { No Person- } \\
\text { Level Covariates }\end{array}$ & $\begin{array}{c}\text { Age, Sex, Family } \\
\text { History, Income, } \\
\text { Education }\end{array}$ & $\begin{array}{c}\text { Age, Sex, Family } \\
\text { History, Income, } \\
\text { Education, Race/ } \\
\text { Ethnicity }\end{array}$ & $\begin{array}{l}\text { Age, Sex, Family } \\
\text { History, Income, } \\
\text { Education, Race/ } \\
\text { Ethnicity, Physical } \\
\text { Activity, Diet }{ }^{\dagger}\end{array}$ & $\begin{array}{c}\text { Age, Sex, Family } \\
\text { History, Income, } \\
\text { Education, Race/ } \\
\text { Ethnicity, Physical } \\
\text { Activity, Diet, }{ }^{\dagger} \text { Body } \\
\text { Mass Index }\end{array}$ \\
\hline 1 & $\begin{array}{l}\text { Neighborhood physical } \\
\text { activity resources }\end{array}$ & $-39(-54$ to 17$)$ & $-28(-45$ to -4$)$ & $-21(-41$ to 6$)$ & $-14(-36$ to 17$)$ & $-6(-30$ to 27$)$ \\
\hline 2 & $\begin{array}{l}\text { Neighborhood healthy } \\
\text { foods resources }{ }^{\ddagger}\end{array}$ & $-26(-45$ to 1$)$ & $-11(-33$ to 20$)$ & $5(-23$ to 43$)$ & $10(-20$ to 50$)$ & $22(-10$ to 64$)$ \\
\hline 3 & $\begin{array}{l}\text { Distance to a } \\
\text { neighborhood with } \\
\text { good physical activity } \\
\text { resources }\end{array}$ & $29(14$ to 46$)$ & $20(7$ to 34$)$ & $17(4$ to 31$)$ & $15(2$ to 30$)$ & $14(2$ to 27$)$ \\
\hline 4 & $\begin{array}{l}\text { Distance to a } \\
\text { neighborhood with } \\
\text { good healthy foods } \\
\text { resources }\end{array}$ & 17 (4 to 32$)$ & $9(-3$ to 22$)$ & $2(-9$ to 15$)$ & $0(-11$ to 13$)$ & $3(-7$ to 14$)$ \\
\hline
\end{tabular}

resistance was $17 \%$ lower per increase from the 10 th to 90 th percentile in neighborhood physical activity resources $(\mathrm{CI}=$ $-31 \%$ to $-1 \%$ ). Neighborhood healthy food resources were similarly inversely associated with insulin resistance although the association was attenuated after adjustment for race/ ethnicity. Results also suggested that individual-level diet and 
physical activity mediate the observed associations, both directly and via obesity (BMI). Residing farther from area resources was also associated with insulin resistance, although associations were weaker than for the neighborhood measures.

The magnitude of the association observed (eg, 17\% lower insulin resistance with improvements in the physical activity environment) roughly is equivalent to a cross-sectional increase in insulin resistance associated with a 2.4 $\mathrm{kg} / \mathrm{m}^{2}$ decrease in BMI in this sample. A 1-unit increase in BMI (from 25 to $26 \mathrm{~kg} / \mathrm{m}^{2}$ ) has been associated with at least a $14 \%$ increased risk of diabetes over a 20 -year period. ${ }^{38}$ These results suggest that residing within or near zones where people can engage in physical activity may be protective of insulin resistance and, conversely, the absence of these resources may promote insulin resistance. Based on the items measured in the physical activity scale, the health benefits we observed could be due to factors that promote walking (eg, having walking destinations and a pleasing environment for walking) and availability of facilities such as sports clubs and other places to exercise. These findings are consistent with prior work that documented positive associations between physical activity and neighborhood density of facilities for physical activity, ${ }^{7,8}$ having walking destinations, ${ }^{6,39}$ and a pleasant/attractive environment. ${ }^{40-42}$

Based on the items measured in the healthy foods scale, associations between insulin resistance and availability of healthy foods could be due to the presence of high quality fruits and vegetables and low-fat foods. There is growing evidence that availability and quality of healthy foods is not uniform throughout residential environments ${ }^{27,43}$ and that availability of good quality fresh foods promotes healthy food choices. ${ }^{44}$ Associations with insulin resistance were weaker for healthy food environments than for physical activity environments, but a direct comparison of the 2 exposures is limited due to greater measurement error in the healthy foods resource scale. The healthy foods scale comprised only 3 items (compared with 6 for physical activity) and did not include the range of foods potentially protective of insulin resistance (such as availability/quality of whole-grain foods). Additionally, most study participants reported food-shopping far outside of the 1 mile neighborhood about which residential survey participants had reported. Generally, our stratified results (shopped for food within 1 mile and not owning an automobile) suggested that neighborhood resources for healthy foods had a stronger relationship with insulin resistance when persons were less mobile or unwilling to travel far distances to shop for healthy foods.

There was no evidence that site confounded the relationship between area-resources and insulin resistance (results were the same before and after site-adjustment, not shown). However, associations between insulin resistance and healthy food resources differed by study site - possibly due to site differences in scale and transportation. The magnitude of the healthy foods effect was strongest for residents in New York, where participants reporting shopping for food close to their home and not owning an automobile. Associations did not differ by study site for physical activity resources.

The relationship between area characteristics and insulin resistance likely involves multiple pathways. Teasing apart specific mediating pathways is difficult because of the distal relationships and time lags involved, as well as problems inherent in separating direct and indirect effects in regression analyses. ${ }^{32,45}$ Nevertheless, our results suggest that diet, physical activity, and BMI are mediating variables in the association between area resources and insulin resistance. Associations were attenuated after adjustment for diet and physical activity, and were greatly reduced after adjustment for BMI. In addition, area resources were associated with BMI, person-level physical activity, and diet. Direct physiologic consequences of adiposity are manifested by the high correlation between BMI and insulin resistance. ${ }^{46} \mathrm{BMI}$ is most proximal to insulin resistance in the causal chain leading from area features, through behaviors, to insulin resistance. Thus, it is not surprising that BMI appeared to be the strongest mediator in the pathways we examined between area resources and insulin resistance. In addition, BMI may have accounted for unmeasured aspects of individual-level behaviors or other (unmeasured) pathways that influence insulin resistance.

All estimates of area effects were weakened after adjustment for race/ethnicity (over and above person-level age, sex, income, and education). Whether area-effects should or should not be adjusted for race/ethnicity is debatable. There are several ways through which race/ethnicity may be related to insulin resistance: cultural traditions and preferences that relate to diet and physical activity, genetic influences, or socioeconomic status that can determine residential location. ${ }^{47-50}$ Because neighborhoods are segregated by income and race/ethnicity, it may be difficult or impossible to isolate the independent effects of area resources and race/ethnicity, ${ }^{51-53}$ and thus, adjustment for race/ethnicity could result in underestimation of area effects.

A main strength of this study is its ability to test specific processes through which neighborhood factors may influence health. In contrast to past studies that used census socioeconomic data to characterize areas, our data allowed testing of specific hypotheses that link residential environments with biologic processes. For example, a recent study reported positive associations between insulin resistance and living far from a high-income neighborhood. ${ }^{54}$ Our study provides some evidence that those associations could be due to highincome areas having more resources for physical activity and better availability of healthy foods. In contrast to existing work that has used "objectively" measured resources to characterize areas (eg, proximity to parks and food stores ${ }^{8,41,55,56}$ ), our survey data represented the "lived" experience of residents. Survey items included neighborhood safety and access to and 
quality of resources - thereby representing multiple dimensions of the ways residential environments may impact health.

Another strength of this study is the large populationbased, multiethnic sample. However, exclusion criteria may have resulted in underestimates of associations if excluded persons were more likely to be both insulin resistant and live in lower-resource areas. By design, persons with a history of clinical cardiovascular disease (a condition associated with insulin resistance) were excluded. Persons excluded during analyses due to missing information had higher BMI (likely more insulin resistant) and were more demographically disadvantaged (potentially more likely to live in lower-resource areas). Additionally, because we were interested in predictors of early manifestations of insulin resistance (before the process becomes clinically symptomatic) the main analyses excluded persons treated for diabetes; however, results were generally insensitive to this exclusion (assessed by using impaired fasting glucose/diabetes in place of the homeostasis index as a measure of insulin resistance). Alternately, selfselection into neighborhoods could account for some of the observed results (eg, active individuals tend to self-select themselves into neighborhoods that are suitable for being physical active). ${ }^{6,57}$ Because the ability of persons to choose their neighborhood likely depends on income and race/ethnicity, we attempted to minimize self-selection by adjusting the multivariable model for person-level characteristics. Finally, because this is a cross-sectional study, we cannot determine whether exposure to area features preceded the development of insulin resistance. Insulin resistance likely develops slowly over a long period, ${ }^{38}$ making long-term chronic exposures more relevant than current exposures.

Type 2 diabetes and metabolic abnormalities are becoming more common. This makes it all the more urgent to identify environmental features that may improve diet and physical activity, which in turn may reduce the risk of type 2 diabetes. If the availability of healthy foods and attractive walking destinations can in fact improve insulin resistance, such environmental features may offer an effective health intervention at the neighborhood level.

\section{ACKNOWLEDGMENTS}

We thank the other investigators, staff, and participants of the Multi-Ethnic Study of Atherosclerosis for their valuable contributions. A full list of participating investigators and institutions can be found at http://www.mesa-nhlbi.org.

\section{REFERENCES}

1. Diez Roux AV, Jacobs DR, Kiefe CI. Neighborhood characteristics and components of the insulin resistance syndrome in young adults: the Coronary Artery Risk Development in Young Adults (CARDIA) study. Diabetes Care. 2002;25:1976-1982.

2. Auchincloss AH, Diez Roux AV, Brown DG, et al. Filling the gaps: spatial interpolation of residential survey data in the estimation of neighborhood characteristics. Epidemiology. 2007;18:469478.

3. Laraia BA, Siega-Riz AM, Kaufman JS, et al. Proximity of supermarkets is positively associated with diet quality index for pregnancy. Prev Med. 2004;39:869-875.

4. Morland K, Wing S, Diez Roux A. The contextual effect of the local food environment on residents' diets: the Atherosclerosis Risk in Communities Study. Am J Public Health. 2002;92:1761-1767.

5. Morland K, Diez Roux AV, Wing S. Supermarkets, other food stores, and obesity: the Atherosclerosis Risk in Communities Study. Am J Prev Med. 2006;30:333-339.

6. Handy S. 2005. Critical Assessment of the Literature on the Relationships Among Transportation, Land Use, and Physical Activity. TRB Special Report 282 Resource Paper: Does the Built Environment Influence Physical Activity? Examining the Evidence. Transportation Research Board and Institute of Medicine Committee on Physical Activity, Transportation, and Land Use. Available at: http://trb.org/downloads/ sr282papers/sr282Handy.pdf. Accessed November 12, 2007.

7. Sallis JF, Hovell MF, Hofstetter CR, et al. Distance between homes and exercise facilities related to frequency of exercise among San Diego residents. Public Health Rep. 1990;105:179-185.

8. Diez Roux AV, Evenson KR, McGinn AP, et al. Availability of recreational resources and physical activity in adults. Am J Public Health. 2007;97:493-499.

9. Giles-Corti B, Macintyre S, Clarkson JP, et al. Environmental and lifestyle factors associated with overweight and obesity in Perth, Australia. Am J Health Promot. 2003;18:93-102.

10. Bild DE, Bluemke DA, Burke GL, et al. Multi-ethnic study of atherosclerosis: objectives and design. Am J Epidemiol. 2002;156:871-881.

11. Matthews DR, Hosker JP, Rudenski AS, et al. Homeostasis model assessment: insulin resistance and beta-cell function from fasting plasma glucose and insulin concentrations in man. Diabetologia. 1985;28:412-419.

12. Wallace TM, Levy JC, Matthews DR. Use and abuse of HOMA modeling. Diabetes Care. 2004;27:1487-1495.

13. Genuth S, Alberti KG, Bennett P, et al. Follow-up report on the diagnosis of diabetes mellitus. Diabetes Care. 2003;26:3160-3167.

14. Weijnen CF, Rich SS, Meigs JB, et al. Risk of diabetes in siblings of index cases with Type 2 diabetes: implications for genetic studies. Diabet Med. 2002;19:41-50.

15. Laaksonen DE, Lakka HM, Niskanen LK, et al. Metabolic syndrome and development of diabetes mellitus: application and validation of recently suggested definitions of the metabolic syndrome in a prospective cohort study. Am J Epidemiol. 2002;156:1070-1077.

16. Hu G, Lindstrom J, Valle TT, et al. Physical activity, body mass index, and risk of type 2 diabetes in patients with normal or impaired glucose regulation. Arch Intern Med. 2004;164:892-896.

17. Ainsworth BE, Haskell WL, Whitt MC, et al. Compendium of physical activities: an update of activity codes and MET intensities. Med Sci Sports Exerc. 2000;2(9 suppl):S498-S504.

18. Liese AD, Roach AK, Sparks KC, et al. Whole-grain intake and insulin sensitivity: the Insulin Resistance Atherosclerosis Study. Am J Clin Nutr. 2003;78:965-971.

19. Liese AD, Schulz M, Fang F, et al. Dietary glycemic index and glycemic load, carbohydrate and fiber intake, and measures of insulin sensitivity, secretion, and adiposity in the Insulin Resistance Atherosclerosis Study. Diabetes Care. 2005;28:2832-2838.

20. McKeown NM, Meigs JB, Liu S, et al. Carbohydrate nutrition, insulin resistance, and the prevalence of the metabolic syndrome in the Framingham Offspring Cohort. Diabetes Care. 2004;27:538-546.

21. Pereira MA, Jacobs DR Jr, Pins JJ, et al. Effect of whole grains on insulin sensitivity in overweight hyperinsulinemic adults. Am J Clin Nutr. 2002;75:848-855.

22. Slesinski MJ, Subar AF, Kahle LL. Dietary intake of fat, fiber and other nutrients is related to the use of vitamin and mineral supplements in the United States: the 1992 National Health Interview Survey. J Nutr. 1996;126:3001-3008.

23. Mujahid MS, Diez Roux AV, Morenoff JD, et al. Assessing the measurement properties of neighborhood scales: from psychometrics to ecometrics. Am J Epidemiol. 2007;165:858-867.

24. Duncan GJ, Raudenbush S. Neighborhoods and adolescent development: how can we determine the links? In: Booth A, Crouter AC, eds. Does it Take a Village? Community Effects on Children, Adolescents, and Families. State College, PA: Pennsylvania State University Press; 2001:105-136. 
25. Raudenbush SW. The quantitative assessment of neighborhood social environments. In: Kawachi I, Berkman LB, eds. Neighborhoods and Health. New York: Oxford University Press; 2003:132-146.

26. InfoUSA. Database of US Businesses. Vol. 2003 InfoUSA, Inc.

27. Moore LV, Diez Roux AV. Associations of neighborhood characteristics with the location and type of food stores. Am J Public Health. 2006;96: 325-331.

28. Massey DS, Fischer MJ. How segregation concentrates poverty. Ethnic Racial Stud. 2000;23:670-691.

29. Handy SL, Clifton KJ. Local shopping as a strategy for reducing automobile travel. Transportation. 2001;28:317-346.

30. Hiscock R, Macintyre S, Kearns A, et al. Means of transport and ontological security: Do cars provide psycho-social benefits to their users? Transportation Research Part D. 2002;7:119-135.

31. Bostock L. Pathways of disadvantage? Walking as a mode of transport among low-income mothers. Health Soc Care Community. 2001;9: $11-18$.

32. Cole SR, Hernan MA. Fallibility in estimating direct effects. Int $J$ Epidemiol. 2002;31:163-165.

33. Hastie TJ. Generalized additive models. In: Chambers J, Hastie T, eds. Statistical Models in S. Wadsworth \& Brooks/Cole Computer Science Series. Pacific Grove, CA: Wadsworth \& Brooks/Cole; 1992:249-308.

34. Spiegelman D, Hertzmark E. Easy SAS calculations for risk or prevalence ratios and differences. Am J Epidemiol. 2005;162:199-200.

35. Clayton D, Kaldor J. Empirical bayes estimates of age-standardized relative risks for use in disease mapping. Biometrics. 1987;43:671-681.

36. Littell R, Milliken G, Stroup W, et al. SAS System for Mixed Models. Cary, North Carolina: SAS Institute Inc.; 1996.

37. Bailey TC, Gatrell AC. Interactive Spatial Data Analysis. Hoboken, NJ: Wiley; 1995.

38. Lyssenko V, Almgren P, Anevski D, et al. Predictors of and longitudinal changes in insulin sensitivity and secretion preceding onset of type 2 diabetes. Diabetes. 2005;54:166-174.

39. Deshpande AD, Baker EA, Lovegreen SL, et al. Environmental correlates of physical activity among individuals with diabetes in the rural midwest. Diabetes Care. 2005;28:1012-1018.

40. van Lenthe FJ, Brug J, Mackenbach JP. Neighbourhood inequalities in physical inactivity: the role of neighbourhood attractiveness, proximity to local facilities and safety in the Netherlands. Soc Sci Med. 2005;60: 763-775.

41. Hoehner CM, Brennan Ramirez LK, Elliott MB, et al. Perceived and objective environmental measures and physical activity among urban adults. Am J Prev Med. 2005;8(2 suppl 2):105-116.

42. Giles-Corti B, Broomhall MH, Knuiman M, et al. Increasing walking- how important is distance to, attractiveness, and size of public open space? Am J Prev Med. 2005;28:169-176.

43. Horowitz CR, Colson KA, Hebert PL, et al. Barriers to buying healthy foods for people with diabetes: evidence of environmental disparities. Am J Public Health. 2004;94:1549-1554.

44. Zenk SN, Schulz AJ, Hollis-Neely T, et al. Fruit and vegetable intake in African Americans income and store characteristics. Am J Prev Med. 2005;29:1-9.

45. Blakely T. Commentary: estimating direct and indirect effects-fallible in theory, but in the real world? Int J Epidemiol. 2002;31:166-167.

46. Abbasi F, Brown BW, Lamendola C, et al. Relationship between obesity, insulin resistance, and coronary heart disease risk. J Am Coll Cardiol. 2002;40:937-943.

47. Lee ZS, Critchley JA, Chan JC, et al. Obesity is the key determinant of cardiovascular risk factors in the Hong Kong Chinese population: cross-sectional clinic-based study. Hong Kong Med J. 2000;6:13-23.

48. Chan JC, Ng MC, Critchley JA, et al. Diabetes mellitus - a special medical challenge from a Chinese perspective. Diabetes Res Clin Pract.2001;54(suppl 1):S19-S27.

49. Caballero AE. Diabetes in the Hispanic or Latino population: genes, environment, culture, and more. Curr Diab Rep. 2005;5:217-225.

50. Palaniappan LP, Carnethon MR, Fortmann SP. Heterogeneity in the relationship between ethnicity, BMI, and fasting insulin. Diabetes Care. 2002;25:1351-1357.

51. Diez Roux AV. Multilevel analysis in public health research. Annu Rev Public Health. 2000;21:171-192.

52. Oakes JM. The (mis)estimation of neighborhood effects: causal inference for a practicable social epidemiology. Soc Sci Med. 2004;58:19291952.

53. Subramanian SV. The relevance of multilevel statistical methods for identifying causal neighborhood effects - Commentary (on Oakes). Soc Sci Med. 2004;58:1961-1967.

54. Auchincloss AH, Diez Roux AV, Brown DG, et al. Insulin resistance is positively associated with distance to wealthy areas: the Multi-Ethnic Study of Atherosclerosis. Am J Epidemiol. 2007;165:389-397.

55. Zenk SN, Schulz AJ, Israel BA, et al. Neighborhood racial composition, neighborhood poverty, and the spatial accessibility of supermarkets in metropolitan Detroit. Am J Public Health. 2005;95:660-667.

56. Morland K, Wing S, Diez Roux A, et al. Neighborhood characteristics associated with the location of food stores and food service places. Am J Prev Med. 2002;22:23-29.

57. Handy S, Cao X, Mokhtarian P. Correlation or causality between the built environment and travel behavior? Evidence from Northern California. Transportation Research Part D. 2005;10:427-444. 